April 2019

\title{
Solution Model for Enhancing the Experiences of Urban First Nations and Métis Patients Accessing and Navigating the Health System for Inflammatory Arthritis Care
}

Cheryl Barnabe

University of Calgary, ccbarnab@ucalgary.ca

Jean Miller

O'Brien Institute for Public Health, jeanleighton@shaw.ca

Sylvia Teare

O'Brien Institute for Public Health, teares@shaw.ca

Casey Eaglespeaker

Alberta Health Services, ceaglesp@hullservices.ca

See next page for additional authors

\section{Recommended Citation}

Barnabe, C. , Miller, J. , Teare, S. , Eaglespeaker, C. , Roland, B. , Eshkakogan, N. , Crowshoe, (. , Lopatina, E. , Marshall, D. (2019).

Solution Model for Enhancing the Experiences of Urban First Nations and Métis Patients Accessing and Navigating the Health System for Inflammatory Arthritis Care. The International Indigenous Policy Journal, 10(2).

DOI: 10.18584/iipj.2019.10.2.3 


\title{
Solution Model for Enhancing the Experiences of Urban First Nations and Métis Patients Accessing and Navigating the Health System for Inflammatory Arthritis Care
}

\begin{abstract}
Health system innovations that better support Indigenous patients, particularly in urban settings, exist in primary health services, but this has not been translated and integrated into specialty care. We sought to identify the experiences of urban First Nations and Métis patients with inflammatory arthritis in accessing and navigating the health system. We used a qualitative research method called Patient and Community Engagement Research Program (PaCER) led by patients using an iterative three phase process: Set, Collect, and Reflect. Initial access and continuity of specialty care can be facilitated with collaboration between primary and specialty care in an urban Indigenous health service model, where health system change was built on culturally responsive models of care.
\end{abstract}

\section{Keywords}

inflammatory arthritis, models of care, Indigenous, urban Indigenous health clinics, PaCER

\section{Creative Commons License}

Creative Commons Attribution-Noncommercial-No Derivative Works 4.0 License

This work is licensed under a Creative Commons Attribution-Noncommercial-No Derivative Works 4.0

License.

\section{Authors}

Cheryl Barnabe, Jean Miller, Sylvia Teare, Casey Eaglespeaker, Brenda Roland, Nicole Eshkakogan, (Lynden) Lindsay Crowshoe, Elena Lopatina, and Deborah Marshall 


\section{Solution Model for Enhancing the Experiences of Urban First Nations and Métis Patients Accessing and Navigating the Health System for Inflammatory Arthritis Care}

Inflammatory arthritis conditions are highly prevalent in Indigenous (First Nations, Métis, and Inuit) populations in Canada (McDougall, Hurd, \& Barnabe, 2017), with double the general population prevalence estimates for conditions such as rheumatoid arthritis (Barnabe, Elias, Bartlett, Roos, \& Peschken, 2008; Barnabe, Jones, et al., 2017) and spondyloarthritis (Barnabe, Jones, et al., 2017). In addition, the phenotype of inflammatory arthritis conditions is described as more severe among Indigenous Peoples: Rheumatoid arthritis is characterized as presenting at an earlier age, having an increased frequency of seropositivity, and having extra-articular features associated with both a more severe prognosis and a predilection for large joint involvement affecting mobility to a greater extent (Hurd \& Barnabe, 2017; Peschken et al., 2010). Even under what are considered ideal circumstances of rheumatology specialty care, with facilitated access to diagnosis and targeted medical treatment in high volume centers, Indigenous patients in Canada are less likely to experience improvements in disease activity measures (Barnabe et al., 2018; Nagaraj et al., 2018). Inflammatory arthritis complications result in higher hospitalization rates for First Nations populations in Canada and are potentially related to insufficiently treated disease as specialty care services are less frequently accessed (Barnabe et al., 2015; Barnabe, Jones, et al., 2017; Loyola-Sanchez, Hurd, \& Barnabe, 2017) and barriers to receiving diseasemodifying medications exist (Barnabe et al., 2016).

The status of determinants of health vary for urban Indigenous patients in relation to their non-urban counterparts (Place, 2012; Tjepkema, 2002). In particular, urban Indigenous patients face disparities in housing, income, and access to services (Firestone, Smylie, Maracle, Spiller, \& O'Campo, 2014; Ontario Federation of Indian Friendship Centers [OFIFC], Ontario Metis Aboriginal Association, \& Ontraio Native Women's Association [ONWA], 2007)—all of which impact arthritis management plans. Access to health services is regarded as a critical determinant of arthritis outcomes. Although there is an impression that health service access is most difficult for Indigenous patients from remote locations, especially in terms of the logistical barriers around accessing providers for diagnosis and management, there are nonetheless specific concerns for Indigenous people residing in urban centers who both experience jurisdictional barriers to care and may experience unacceptable care (Thurston et al., 2014). These concerns are amplified by the perception of mainstream specialty services placing emphasis on technological and biomedical solutions and neglecting the management of complex social situations that are the reality for urban Indigenous patients (McDonald, 2011).

Primary health services have adapted to better serve the urban Indigenous population through the establishment of multidisciplinary urban Indigenous healthcare centers, which incorporate care for physical, mental, emotional, and spiritual wellness (Health Council of Canada, 2012). These centers play an essential role in helping patients navigate complex networks of health and social services, with service delivery based on Indigenous approaches to health and healing (Browne \& Elliott, 2009). They also deliver high-quality service through prioritizing culturally safe and relevant care. However, patients with inflammatory arthritis would still be required to access their rheumatology care at a separate center, where these principles will not necessarily be recognized or supported, which could ultimately result in care disengagement. In light of these issues, the purpose of this research is to inform specialty care systems and providers about the situations urban Indigenous patients face when they access 
inflammatory arthritis care so they can better respond to patients' needs, develop care alliances with patients and primary health service providers, and ultimately resolve care gaps.

This study focuses on understanding the experiences of urban First Nations and Métis patients accessing and navigating the health system for inflammatory arthritis care. Specifically, it focuses on the experiences of patients engaged in a model of care where specialty rheumatology care is provided in the context of an urban Indigenous primary health service. For this study, we employed an innovative qualitative research method called Patient and Community Engagement Research (PaCER). PaCER researchers are individuals who have completed a formal 12-month training program to design and conduct qualitative health research relevant to the health condition they have. As part of their research process, these individuals engage other patients using an established protocol of qualitative inquiry (Marlett \& Emes, 2010; Marlett, Shklarov, Marshall, Santana, \& Wasylak, 2014; Miller, Teare, Marlett, Shklarov, \& Marshall, 2016; Shklarov, Marshall, Wasylak, \& Marlett, 2017). This approach, driven by patients working with patients, brings a collective patient voice to health system change. It results in a shared collective understanding of the research issue that is solidly grounded in patient experience.

\section{Methods}

\section{Methodologic Framework and Study Setting}

The PaCER research method (Marlett \& Emes, 2010) has 3 phases: Set, Collect, and Reflect. In the Set phase, patients clarify the scope and direction of the study, generally using focus groups. Data are then acquired (the Collect phase) from patients using focus groups, narrative interviews, observation, or questionnaires. In the Reflect phase, patients participate in a final focus group to arrive at a common understanding of the findings from the Collect phase and then make suggestions about future research directions and knowledge dissemination. As described above, the PaCER method is rooted in the PaCER researchers' experience with their respective conditions, which helps them identify with the patients they engage during the research process. However, at the time of our study, none of the PaCER researchers had inflammatory arthritis, and none were from First Nations or Métis populations.

Instead, two certified and experienced non-Indigenous PaCERs with osteoarthritis (JM \& ST), who had led a full Set, Collect, and Reflect process in a group of patients with rheumatoid arthritis (Lopatina et al., 2018), were brought on to the research team. They joined two non-Indigenous academic researchers who had previously worked with the PaCER research method (EL \& DM), and two Indigenous academic physicians (CB \& LC) who practice at the Elbow River Healing Lodge, which is an urban Indigenous primary health service in Calgary, Alberta, Canada. These members partnered with two First Nations health professionals (BR \& NE, also a graduate student) from the Indigenous Health Program of Alberta Health Services and an Elder (CE), who was recognized by the urban Indigenous community in Calgary and Chair of the Alberta Health Services Wisdom Council, to implement a modified PaCER research process at the Elbow River Healing Lodge. The Elbow River Healing Lodge is administrated by the Indigenous Health Program of Alberta Health Services. Within the Elbow River Healing Lodge, a monthly arthritis specialty clinic accepts referrals both through a triage process (Hazlewood et al., 2016) and self-referral processes (Barnabe, Lockerbie, Erasmus, \& Crowshoe, 2017). Self-identified urban First Nations and Métis patients with inflammatory arthritis conditions were recruited from this clinic for the study by a research assistant. 


\section{Ethics Approval and Consent to Participate}

The University of Calgary Conjoint Health Research Ethics Board approved this study (REB 14-0478). A formal research agreement set out the roles and responsibilities of the investigators to the urban First Nations and Métis population and the Indigenous Health Program of Alberta Health Services on behalf of the Elbow River Healing Lodge. Individual patient consent was obtained.

\section{Reflect Phase with First Nation and Métis Patients}

With the urban First Nations and Métis patients recruited from the Elbow River Healing Lodge, we explored experiences accessing and navigating the health care system for their arthritis using an adapted interview guide from the non-Indigenous Rheumatoid Arthritis Study that had previously been conducted (Lopatina et al., 2018). This guide addressed topics relating to the impact of inflammatory arthritis on the participants' lives, self-management strategies, their journeys to inflammatory arthritis diagnosis, and their experiences with medication. Themes that had been identified in the nonIndigenous study were specifically explored with the participants of this study. These themes included challenges in:

a. Initial access to rheumatology care;

b. Ongoing access to rheumatology care;

c. Information about the disease and resources for those living with arthritis;

d. Fear of the future; and

e. Collaborative and continuous care (Lopatina et al., 2018).

Individual face-to-face interviews were led by the Indigenous health professionals and the Elder and were audio recorded. The PaCER researcher was present in the room and recorded notes as the interviews proceeded but did not lead the questioning. The interviews were 0.5 to 2 hours in duration and were held in a meeting room at the Elbow River Healing Lodge.

\section{Analysis and Validation}

First, the PaCER researcher conducted preliminary coding on the interviews and field notes based on both elements of Glaser and Strauss's (1967) grounded theory method (Hallberg, 2006) and the framework developed in the non-Indigenous study (Lopatina et al., 2018). These preliminary codes were reviewed with a second PaCER researcher who has osteoarthritis. Then, the resulting preliminary analysis was presented to the First Nations health professionals and the Elder who conducted the interviews; they provided further contextual clarity regarding both the content of the interviews and the interpretations of them. Next, the PaCER researchers summarized these findings, with further feedback and revision from the First Nations health professionals and the Elder, who confirmed that the synthesis reflected the interviews. Recommendations were then drafted by the whole group. Finally, the results and recommendations were reviewed with leadership from the PaCER program and the broader research team, which includes two Indigenous faculty members and an Indigenous graduate student. These multiple rounds of review were conducted to ensure authentic representation of identified themes and incorporation of Indigenous perspectives in the research. 


\section{Results}

\section{Participants}

In total, 18 people with inflammatory arthritis accepted the invitation to participate (14 women and 4 men). In total, 11 people were interviewed and the remaining 7, who had accepted the invitation to participate, did not arrive for the interview. The 11 participants were all female, ranged from 39 to 70 years of age, and all were First Nations or Métis. The participants reflected a spectrum of arthritis conditions, ranging from recent onset to established inflammatory arthritis diagnoses. Their experiences of having inflammatory arthritis, of self-management, and of their journeys accessing and navigating the healthcare system for the management of their conditions are summarized below.

\section{Experience of Inflammatory Arthritis}

Inflammatory arthritis was seen to impact all aspects of the participants' lives, from how they managed daily tasks to how they managed their relationships with others. One participant described the allencompassing nature of living with inflammatory arthritis as something that "takes up space in her brain" (Participant C5), as she always needs to plan ahead. The pain, fatigue, and immobility of inflammatory arthritis affected her ability to prepare meals, maintain personal hygiene and cleanliness in the home, maintain employment, and have restful sleep. One participant described her fatigue as feeling like "a balloon that got punctured" (Participant C11). Participants also spoke of how inflammatory arthritis had impacted their relationships with family members and friends. One participant reflected on her personality changing, noting that she had become more reclusive; another stated that she was reluctant to even enter a romantic relationship, as "sex is not an option" (Participant C8). One participant expressed guilt and a feeling that her younger children were being "cheated" (Participant C10), since she was neither able to complete activities she had done with her older children nor able to care for her younger children without relying on her older children's help.

\section{Self-Management Strategies}

Participants discussed a variety of modalities to manage their symptoms, including topical and thermal therapies, aromatherapy, massage, and vitamins. Several people spoke of meditation and rest, eating a healthy diet, and getting regular exercise. One participant said her self-management strategy was to "live differently and naturally" (Participant C8).

\section{The Journey of Accessing and Navigating the Healthcare System for Inflammatory Arthritis}

Initial access to rheumatology care. Many participants had received an inflammatory arthritis diagnosis prior to engaging in care at the Elbow River Healing Lodge, which meant that their experiences were of being referred through the usual care pathway of primary to specialty care in a general population clinic setting. Participants perceived delays in accessing care as related to either primary care providers' unfamiliarity with inflammatory arthritis conditions or a general reluctance to refer patients to rheumatologists. For Participant C3, when asked to speculate why she had not been referred to a rheumatologist, she thought it might have been because, at the time she was diagnosed, doctors did not know about rheumatoid arthritis and there were few doctors on reserves. Participant C6 recalled that her 
family doctor said she likely had the onset of rheumatoid arthritis but was not certain and did not refer her to a rheumatologist to confirm the diagnosis.

Access to rheumatology care was further complicated by participants' experiences of discrimination and racism. Participants perceived that providers did not believe patients' reports of pain or the inflammatory arthritis diagnoses that were previously made in other care settings. Participant C8, for example, had been treated for over 10 years for rheumatoid arthritis in another province, but during a hospitalization her diagnosis was revised to fibromyalgia; following this, her medications for rheumatoid arthritis were discontinued for a full 2 years until she could re-engage with rheumatology care at the Elbow River Healing Lodge and have her treatment re-initiated.

Another complication was patients' own reluctance to seek care. Participant C6, who had not been referred to specialty care despite the suspicion of inflammatory arthritis, stopped going to her primary care provider because she thought they were too eager to give her prescription pain medication without addressing her main concerns. Participants reported downplaying their pain and just putting up with their symptoms, which was something they had witnessed their family members do in order to avoid contact with the health system. Participant C5 noted, she "just keeps going," and Participant C9 said that she "forges on." Some participants reported masking their pain with other substances or ascribing their pain to another cause. Participant $\mathrm{C} 1$ addressed pre-existing joint pain with alcohol and drugs; Participant C8 attributed her pain to previous motor vehicle collisions. Some found that health professionals assumed their symptoms were caused by addiction problems. Participant C9 described her experience: "I don't like it when you go in and you have a problem and they assume you have an addiction problem."

For participants who had accessed inflammatory arthritis care through the Elbow River Healing Lodge, their model of care facilitated referral to the Arthritis Clinic, which resulted in negligible wait times for appointments (Barnabe, Lockerbie, et al., 2017). When asked about navigating the health care system through this model of care, Participant C3 said: "Actually I just kind of zoomed through it. I'm very grateful for that, (I was) one of the fortunate ones ... just zoomed through the system: the doors just opened for me." Racism and stereotyping were not perceived in this model of care.

Ongoing access to rheumatology care. Participants spoke highly of the ongoing access they had to clinical services at the Elbow River Healing Lodge. Patients felt welcome to return as frequently as they needed and were appreciative of both the multiple modes of communication with the health professionals (e.g., email) and the primary health care providers' availability when the rheumatologist could not be immediately accessed. One participant (Participant C11) stated, "the help I've gotten and the access has been very good."

Information about disease and resources for those living with arthritis. Few First Nations and Métis participants expressed need for additional knowledge about their disease or additional resources for disease management. Participants spoke of receiving support and information from their family members, friends, and their faith, as well as gathering information from participating in community programs or searching the internet. When asked what else could help her deal with her arthritis, Participant C3 said: "God the Creator: I can't think of anything else." Similarly, Participant C2 said, "if there is such thing as a God, then he/she should show up and just take the pain away. He should be like a 
parent and not want to see you in pain." Two participants expressed interest in the supportive and traditional wellness practices provided at the Elbow River Healing Lodge.

Fear. In the non-Indigenous study, this theme reflected patients' fears about future disease management, such as which medications might be required and their potential side effects, medication options becoming exhausted, or not receiving the best medications for their arthritis. In this study, First Nations and Métis patients said they experienced difficulties with incomplete pain relief, perceived ineffectiveness of arthritis therapies, unwanted side effects, and a fear of becoming addicted to their medications. Participants' experiences with medication effectiveness were reflected by one participant's observation that "medications are sort of trial and error" (Participant C5). This participant stated that she knew her arthritis would progress and all she could do was "just cope and hope." Other participants said their medications would simply take the edge off their pain and, in some instances, were ineffective, causing them to either take excessive doses in hopes of obtaining relief or to abandon therapy entirely. One participant noted her prior experience with a physician who, when she revealed that she had discontinued or self-titrated the physician recommended medication, was frustrated with her because it put continuity of care at risk. Participants also perceived discrimination as a threat to ongoing medication access; one participant felt that, based on her race, her previous health care provider had withheld medications. She explained her understanding of the provider's mindset: "We won't give you something because we don't want you to become addicted to it" (Participant C9).

Issues of medication access were also brought up by the urban First Nations and Métis participants. Several expressed their frustration at delays instigated by federal government processes for medication approvals, as well as what they perceived as inconsistent lengths of review for medication approvals based on the type of medication prescribed - which delayed access to necessary treatment. ${ }^{1}$ Medication costs were still a relevant factor, with one participant stating that if her medication costs were not covered, she would have to do without treatment and endure increased pain.

Collaborative and continuous care. The care model at the Elbow River Healing Lodge fosters collaboration and continuity across the system; these kinds of experience dominated participants' discussions within this theme. The direct relationship between primary and specialty care, together with the approach to care delivery at the Elbow River Healing Lodge, was perceived to be a critical component of continuity of care. Participant C11, for example, stated that once she started coming to the Elbow River Healing Lodge, "everything levelled out and everything was OK." Another participant, Participant C9, said, "when I'm feeling overwhelmed, I come here." She reported feeling safe at the clinic, noting that the staff were like family. She said the staff are honest with her and "they go out of their way to make you feel good." Participant C9 went on to say that she can express herself freely and without

\footnotetext{
${ }^{1}$ In Canada, First Nations with Indian Status and Inuit persons receive medication coverage through the federal government's Non-Insured Health Benefits (NIHB) program (Government of Canada, n.d.). The NIHB program is the payer of last resort; thus, any other private or public sources of funding for medications must be accessed prior to NIHB providing coverage. The formulary for first-line disease modifying anti-rheumatic drugs is open benefit and can be dispensed from pharmacies without prior approval. However, biologic medications are "limited use" and NIHB will request additional information from the treating physician, as well as confirming the stated medication history, prior to approving a claim for these agents.
} 
judgment at the clinic. She was given the time she needed to address her concerns and felt the clinic staff "always want to help you go in the right direction."

An additional element brought up by urban First Nations and Métis patients was a requirement for the health system and providers to provide culturally appropriate care. Participants expressed great interest in having the health system bridge traditional and Western medicine paradigms. Many of the participants expressed their disconnection from traditional practices; as one participant put it, she was "raised White" (Participant C1). Participants were eager to bring the spiritual, emotional, and physical aspects of their lives together to achieve health. Participants who engaged in traditional practices were appreciative of the support that the Elbow River Healing Lodge staff expressed for these practices.

\section{Discussion}

This article presents the experiences of urban First Nations and Métis patients who accessed an Indigenous-focused health service for inflammatory arthritis care. Through our study, we were able to highlight positive patient experiences within a model of care that involves the provision of rheumatology specialty services in an urban multidisciplinary Indigenous primary health service. This supportive model of care facilitated access to care, continuity of care, and collaboration, all while addressing care needs and recognizing the value of traditional approaches to health and wellness. In prior research, we worked with First Nations and Métis people from rural and urban centers with either osteoarthritis or inflammatory arthritis in order to better understand the processes, barriers, and facilitators in order to inform an arthritis care framework (Thurston et al., 2014). These patients proposed a model of care that embodied culturally appropriate practices and provided innovative services to resolve care barriers. This finding appears to hold true based on our data from the study discussed in this article, as well

Urban Indigenous primary health services are models of care developed to provide high quality care grounded in the social and cultural realities of Indigenous patients. Structural adaptations within the clinical model are at the core of providing culturally competent and safe care that is responsive to the needs of urban Indigenous patients. An ethnographic study of urban Indigenous primary health care centers by Browne et al. (2016) found contextually tailored, culturally safe, trauma- and violenceinformed, and inequity-responsive care to be essential in achieving equity-oriented and effective services. Models of care in rheumatology in Canada have been widely discussed in recent years for two primary reasons. The first is the shortage of rheumatology specialists (Barber et al., 2017). The second is the large body of evidence informing current treatment guidelines, which supports early diagnosis and institution of appropriate therapy, along with frequent and systematic disease activity monitoring to identify when and if treatment needs to be escalated (Bykerk et al., 2012). In 2014, the Arthritis Alliance of Canada (2014) defined a pan-Canadian approach to inflammatory arthritis models of care, which is heavily weighted towards navigating patients to specialty care through which a rheumatologist will provide ongoing management and patients will be responsible for adhering to the prescribed treatment. The novelty of our work is that it combines these approaches in an environment that is supportive to urban Indigenous patients (Barnabe, Lockerbie, et al., 2017), and it is one proposed strategy to resolve existing inflammatory arthritis care gaps. It is acknowledged, however, that beneficial models of care developed in small scale must ultimately be shown to meet the health service needs of the larger population base (Henderson, Montesanti, Crowshoe, \& Leduc, 2018). 
Despite the overall positive experiences of the model of care reported by participants, there was still evidence for tension and discomfort around individual decision-making for pharmacotherapy for inflammatory arthritis. Specifically, participants shared experiences of incomplete therapeutic effect, the occurrence of side effects, and fears of addiction. In the field of diabetes research, a qualitative study of Indigenous patients linked doctors being overly prescriptive with experiences of authoritarianism encountered in the residential schools, or as an indication of the physician's unwillingness to communicate or interact deeply with the patient (Jacklin et al., 2017). This negative association with traditional Western medical practice requires further exploration specifically in the treatment of inflammatory arthritis conditions because it is commonly treated with several medications concurrently and chronically, including those with immune-suppressive effects and those providing acute symptomatic relief. An emerging literature specific to Indigenous populations has suggested solutions to the problems encountered in health care settings through health literacy innovations (Crengle et al., 2018; Lambert et al., 2014) and patient-centered care plans that involve shared decision-making strategies (Jull et al., 2013; Jull et al., 2015). These may be beneficial in the context of inflammatory arthritis and should be the subject of future studies.

Based on what participants noted, we propose solutions in Table 1 that could support inflammatory arthritis care access and health system navigation for urban First Nations and Métis patients. These solutions may be applicable to urban Indigenous populations internationally who face similar issues in accessing specialty care. These solutions encompass Indigenous patient priorities and the evidence base of rheumatology practice regarding:

- The importance of early diagnosis and treatment of inflammatory arthritis and facilitated referral mechanisms to specialty care;

- The continuity of specialty care provision, especially in collaboration with primary care teams;

- The accessibility of traditional health and wellness strategies;

- The enhancement of discussions around pharmacotherapy; and

- Advocacy for improved medication access.

For urban First Nations and Métis patients, it is critical that these elements of inflammatory arthritis care are provided in culturally appropriate environments with services and systems that embody cultural safety.

Limitations of this study include the adaptation of the PaCER methodology so that the initial Set and Collect research phases were first informed by a Western lens from the Set, Collect, and Reflect steps carried out by non-Indigenous PaCER researchers with the non-Indigenous rheumatoid arthritis patients. Subsequently, the non-Indigenous PaCER researchers were partnered with First Nations health professionals and an Elder through an Indigenous health clinic in order to conduct interviews with First Nations and Métis patients and interpret the results collaboratively. The patients participating in the research were reflective of the First Nations and Métis patients engaged in rheumatology care in an urban Indigenous clinic, but our results may not be generalizable to other settings. 
Table 1. Summary of Experiences of Urban First Nations and Métis Inflammatory Arthritis Patients in Accessing and Navigating the Health System, and Proposed Solution Model for Existing Challenges

\begin{tabular}{|c|c|c|}
\hline Themes & $\begin{array}{c}\text { Experiences of Urban } \\
\text { First Nations and Métis } \\
\text { Inflammatory Arthritis Patients }\end{array}$ & Solution Model \\
\hline \multirow[t]{3}{*}{$\begin{array}{l}\text { Initial access to } \\
\text { rheumatology care }\end{array}$} & $\begin{array}{l}\text { Reluctance on the part of patients to seek care } \\
\text { Delay in recognition of inflammatory arthritis } \\
\text { in primary care }\end{array}$ & $\begin{array}{l}\text { Provider and public awareness program } \\
\text { of the importance of early diagnosis and } \\
\text { treatment }\end{array}$ \\
\hline & $\begin{array}{l}\text { Wait time for initial appointment } \\
\text { Discrimination and experiences of racism }\end{array}$ & $\begin{array}{l}\text { Facilitated mechanism of referral from } \\
\text { primary to specialty care, and alternative } \\
\text { models of direct access to specialty care }\end{array}$ \\
\hline & $\begin{array}{l}\text { Positive experience with no perceived racism } \\
\text { and stereotyping among participants who had } \\
\text { accessed inflammatory arthritis care through } \\
\text { the urban Indigenous primary health service } \\
\text { and its model of integrated specialty care }\end{array}$ & $\begin{array}{l}\text { Culturally appropriate and racism-free } \\
\text { services }\end{array}$ \\
\hline $\begin{array}{l}\text { Ongoing access to } \\
\text { rheumatology care }\end{array}$ & $\begin{array}{l}\text { Positive experience with continuity of access } \\
\text { in their model of care }\end{array}$ & $\begin{array}{l}\text { Team approach to care } \\
\text { Multiple modes of contact }\end{array}$ \\
\hline $\begin{array}{l}\text { Information about the } \\
\text { disease and resources for } \\
\text { those living with arthritis }\end{array}$ & $\begin{array}{l}\text { Familial support } \\
\text { Interest in supportive and traditional wellness } \\
\text { practices }\end{array}$ & $\begin{array}{l}\text { Education and resource coordination } \\
\text { within the community and medical home }\end{array}$ \\
\hline Fear & $\begin{array}{l}\text { Incomplete pain relief } \\
\text { Perceived ineffectiveness of arthritis therapies } \\
\text { Unwanted side effects }\end{array}$ & $\begin{array}{l}\text { Enhanced communication and shared- } \\
\text { decision making strategies } \\
\text { Culturally appropriate and racism-free } \\
\text { services }\end{array}$ \\
\hline & $\begin{array}{l}\text { Fear of addiction to medications } \\
\text { Delays in the federal processes for medication } \\
\text { approvals } \\
\text { Medication costs as a barrier to treatment } \\
\text { Discrimination as a perceived threat to } \\
\text { ongoing medication access }\end{array}$ & $\begin{array}{l}\text { Physician advocacy to payers for timely } \\
\text { access to advanced therapies } \\
\text { Cost coverage for medications }\end{array}$ \\
\hline $\begin{array}{l}\text { Collaborative and } \\
\text { continuous care }\end{array}$ & $\begin{array}{l}\text { Positive experience of collaborative and } \\
\text { continuous care in the care model } \\
\text { Requirement for the health system and } \\
\text { providers to incorporate culturally } \\
\text { appropriate care }\end{array}$ & $\begin{array}{l}\text { Specialty care integrated in primary } \\
\text { health service } \\
\text { Culturally appropriate and racism-free } \\
\text { services } \\
\text { Patient empowerment } \\
\text { Availability of traditional wellness } \\
\text { strategies }\end{array}$ \\
\hline
\end{tabular}


In summary, we have shared the positive results and impacts of a culturally responsive model of care to facilitate access and continuity of specialty care for Indigenous patients with arthritis, while highlighting the need to improve decision-making support around pharmacotherapy to optimize inflammatory arthritis management. We share positive results on the impact of a culturally responsive model of care to facilitate access and continuity of specialty care for Indigenous patients with arthritis, while highlighting the need to improve decision support around pharmacotherapy to optimize inflammatory arthritis management. Culturally appropriate and racism-free services, team-based care approaches integrating primary and specialty services, and strategies to enhance knowledge about arthritis and its' management can support optimal patient care.

\section{References}

Arthritis Alliance of Canada. (2014). A pan-Canadian approach to inflammatory arthritis models of care. Retrieved from www.arthritisalliance.ca

Barber, C. E., Jewett, L., Badley, E. M., Lacaille, D., Cividino, A., Ahluwalia, V., ... Marshall, D. A. (2017). Stand up and be counted: Measuring and mapping the rheumatology workforce in Canada. The Journal of Rheumatology, 44(2), 248-257. doi: https://doi.org/10.3899/jrheum.160621

Barnabe, C., Elias, B., Bartlett, J., Roos, L., \& Peschken, C. (2008). Arthritis in Aboriginal Manitobans: Evidence for a high burden of disease. The Journal of Rheumatology, 35(6), 1145-1150.

Barnabe, C., Healy, B., Portolesi, A., Kaplan, G. G., Hemmelgarn, B., \& Weaselhead, C. (2016). Claims for disease-modifying therapy by Alberta non-insured health benefits clients. BMC Health Services Research, 16(1), 430. doi: https://doi.org/10.1186/s12913-016-1685-y

Barnabe, C., Hemmelgarn, B., Jones, C. A., Peschken, C. A., Voaklander, D., Joseph, L., ... Marshall, D. A. (2015). Imbalance of prevalence and specialty care for osteoarthritis for First Nations people in Alberta, Canada. The Journal of Rheumatology, 42(2), 323-328. doi: https://doi.org/10.3899/jrheum.140551

Barnabe, C., Jones, C. A., Bernatsky, S., Peschken, C. A., Voaklander, D., Homik, J., ... Hemmelgarn, B. (2017). Inflammatory arthritis prevalence and health services use in the First Nations and nonFirst Nations populations of Alberta, Canada. Arthritis Care \& Research, 69(4), 467-474. doi: https://doi.org/10.1002/acr.22959

Barnabe, C., Lockerbie, S., Erasmus, E., \& Crowshoe, L. (2017). Facilitated access to an integrated model of care for arthritis in an urban Aboriginal population. Canadian Family Physician, 63(9), 699-706.

Barnabe, C., Zheng, Y., Ohinmaa, A., Crane, L., White, T., Hemmelgarn, B., ... Maksymowych, W. P. (2018). Effectiveness, complications, and costs of rheumatoid arthritis treatment with biologics 
in Alberta: Experience of Indigenous and non-Indigenous patients. The Journal of Rheumatology, 45(10), 1344-1352. doi: https://doi.org/10.3899/jrheum.170779

Browne, A. J., Varcoe, C., Lavoie, J., Smye, V., Wong, S. T., Krause, M., ... Fridkin, A. (2016). Enhancing health care equity with Indigenous populations: Evidence-based strategies from an ethnographic study. BMC Health Services Research, 16(1), 544. 10.1186/s12913-016-1707-9

Browne, A. J., McDonald, H., \& Elliott, D. (2009). First Nations Urban Aboriginal health research discussion paper. A Report for the First Nations Centre, National Aboriginal Health Organization. Retrieved from

https://open.library.ubc.ca/cIRcle/collections/facultyresearchandpublications/52383/items/ $\underline{1.0084587}$

Bykerk, V. P., Akhavan, P., Hazlewood, G. S., Schieir, O., Dooley, A., Haraoui, B., ... Bombardier, C. (2012). Canadian Rheumatology Association recommendations for pharmacological management of rheumatoid arthritis with traditional and biologic disease-modifying antirheumatic drugs. The Journal of Rheumatology, 39(8), 1559-1582.

doi: https://doi.org/10.3899/jrheum.110207

Crengle, S., Luke, J. N., Lambert, M., Smylie, J. K., Reid, S., Harre-Hindmarsh, J., \& Kelaher, M. (2018). Effect of a health literacy intervention trial on knowledge about cardiovascular disase medications among Indigenous Peoples in Australia,Canada and New Zealand. BMJ Open, $8(1)$, e018569. doi: https://doi.org/10.1136/bmjopen-2017-018569

Firestone, M., Smylie, J., Maracle, S., Spiller, M., \& O'Campo, P. (2014). Unmasking health determinants and health outcomes for urban First Nations using respondent-driven sampling. BMJ Open, 4(7), e004978. doi: https://doi.org/10.1136/bmjopen-2014-004978

Glaser, B. G., \& Strauss, A. L. (1967). The discovery of grounded theory. Strategies for qualitative research. New Brunswick: Aldine Transaction, Inc. Network.

Government of Canada. (n.d.). Benefits information: Non-Insured Health Benefits. Retrieved from https://www.canada.ca/en/indigenous-services-canada/services/first-nations-inuithealth/non-insured-health-benefits/benefits-information.html

Hallberg, L. (2006). The core category of grounded theory: Making constant comparisons. International Journal of Qualitative Studies on Health and Well-being, 1, 141-148. doi: $\underline{\text { https://doi.org/10.1080/17482620600858399 }}$

Hazlewood, G. S., Barr, S. G., Lopatina, E., Marshall, D. A., Lupton, T. L., Fritzler, M. J., ... Martin, L. (2016). Improving appropriate access to care with central referral and triage in rheumatology. Arthritis Care \& Research, 68(10), 1547-1553. doi: https://doi.org/10.1002/acr.22845

Health Council of Canada. (2012). Empathy, dignity and respect. Creating cultural safety for Aboriginal people in urban health care. Retrieved from https://healthcouncilcanada.ca/files/Aboriginal_Report_EN_web_final.pdf 
Henderson, R., Montesanti, S., Crowshoe, L., \& Leduc, C. (2018). Advancing Indigenous primary health care policy in Alberta, Canada. Health Policy, 122(6), 638-644. doi: https://doi.org/10.1016/j.healthpol.2018.04.014

Hurd, K., \& Barnabe, C. (2017). Systematic review of rheumatic disease phenotypes and outcomes in the Indigenous populations of Canada, the USA, Australia and New Zealand. Rheumatology international, 37(4), 503-521. doi: https://doi.org/10.1007/s00296-016-3623-z

Jacklin, K. M., Henderson, R. I., Green, M. E., Walker, L. M., Calam, B., \& Crowshoe, L. J. (2017). Health care experiences of Indigenous people living with type 2 diabetes in Canada. CMAJ: Canadian Medical Association Journal = Journal de l'Association Medicale Canadienne, 189(3), E106-E112. doi: https://doi.org/10.1503/cmaj.161098

Jull, J., Crispo, J., Welch, V., MacDonald, H., Brascoupe, S., Boyer, Y., \& Stacey, D. (2013). Interventions for Indigenous Peoples making health decisions: A systematic review. Pimatisiwin: A Journal of Aboriginal and Indigenous Community Health, 11(3), 539-554.

Jull, J., Giles, A., Minwaashin Lodge, the Aboriginal Women's Support Centre, Boyer, Y., \& Stacey, D. (2015). Cultural adaptation of a shared decision making tool with Aboriginal women: A qualitative study. BMC Medical Informatics and Decision Making, 15, 1. doi: https://doi.org/10.1186/s12911-015-0129-7

Lambert, M., Luke, J., Downey, B., Crengle, S., Kelaher, M., Reid, S., \& Smylie, J. (2014). Health literacy: Health professionals' understandings and their perceptions of barriers that Indigenous patients encounter. BMC Health Services Research, 14, 614. doi: https://doi.org/10.1186/s12913-014-0614-1

Lopatina, E., Miller, J. L., Teare, S. R., Marlett, N. J., Patel, J., Barber, C. E. H., ... Marshall, D. A. (2018). The voice of patients in system redesign: A case study of redesigning a centralized system for intake of referrals from primary care to rheumatologists for patients with suspected rheumatoid arthritis. Health Expectations, 1-16. doi: https://doi.org/10.1111/hex.12855

Loyola-Sanchez, A., Hurd, K., \& Barnabe, C. (2017). Healthcare utilization for arthritis by indigenous populations of Australia, Canada, New Zealand, and the United States: A systematic review. Seminars in Arthritis and Rheumatism, 46(5), 665-674. doi: https://doi.org/10.1016/j.semarthrit.2016.10.011

Marlett, N., \& Emes, C. (2010). Grey matters. Calgary, AB: University of Calgary Press.

Marlett, N., Shklarov, S., Marshall, D., Santana, M. J., \& Wasylak, T. (2014). Building new roles and relationships in research: A model of patient engagement research. Quality of Life Research, 24(5),1057-1067. doi: https://doi.org/10.1007/s11136-014-0845-y

McDonald, H. L. (2011). Arthritis, aches and pains, and arthritis services: Experiences from within an urban First Nations community (Doctoral dissertation). University of British Columbia, Vancouver. 
McDougall, C., Hurd, K., \& Barnabe, C. (2017). Systematic review of rheumatic disease epidemiology in the Indigenous populations of Canada, the United States, Australia, and New Zealand. Seminars in Arthritis and Rheumatism, 46(5), 675-686.

doi: https://doi.org/10.1016/j.semarthrit.2016.10.010

Miller, J. L., Teare, S. R., Marlett, N., Shklarov, S., \& Marshall, D. A. (2016). Support for living a meaningful life with osteoarthritis: A patient-to-patient research study. Patient, 9(5), 457-464. doi: https://doi.org/10.1007/s40271-016-0169-9

Nagaraj, S., Barnabe, C., Schieir, O., Pope, J., Bartlett, S. J., Boire, G., ... Canadian Early Arthritis Cohort Study Investigators. (2018). Early rheumatoid arthritis presentation, treatment, and outcomes in Aboriginal patients in Canada: A Canadian Early Arthritis Cohort Study Analysis. Arthritis Care \& Research, 70 (8), 1245-1250. doi: https://doi.org/10.1002/acr.23470

Ontario Federation of Indian Friendship Centers (OFIFC), Ontario Metis Aboriginal Association, \& Ontraio Native Women's Association (ONWA). (2007). Urban Aboriginal Task Force final report. Retrieved from http://ofifc.org/sites/default/files/docs/UATFOntarioFinalReport.pdf

Peschken, C. A., Hitchon, C. A., Robinson, D. B., Smolik, I., Barnabe, C. R., Prematilake, S., \& ElGabalawy, H. S. (2010). Rheumatoid arthritis in a North American Native population: Longitudinal followup and comparison with a White population. The Journal of Rheumatology, 37(8), 1589-1595. doi: https://doi.org/10.3899/jrheum.091452

Place, J. (2012). The health of Aboriginal people residing in urban areas. Retrieved from https://www.ccnsa-nccah.ca/docs/emerging/RPT-HealthUrbanAboriginal-Place-EN.pdf

Shklarov, S., Marshall, D. A., Wasylak, T., \& Marlett, N. J. (2017). "Part of the team": Mapping the outcomes of training patients for new roles in health research and planning. Health Expectations, 20(6), 1428-1436. doi: https://doi.org/10.1111/hex.12591

Thurston, W. E., Coupal, S., Jones, C. A., Crowshoe, L. F., Marshall, D. A., Homik, J., \& Barnabe, C. (2014). Discordant Indigenous and provider frames explain challenges in improving access to arthritis care: A qualitative study using constructivist grounded theory. International Journal for Equity in Health, 13(1), 46. doi: https://doi.org/10.1186/1475-9276-13-46

Tjepkema, M. (2002). The health of the off-reserve Aboriginal population. Health Reports, 13, 1-17. Retrieved from https://www150.statcan.gc.ca/n1/pub/82-003-s/2002001/pdf/82-003s2002004-eng.pdf 